http://dx.doi.org/10.21707/gs.v11.n01a14

\title{
SOlIDARIEDADE E GovernaNÇA AMBIENTAIS NA GESTÃo DE AMBIENTES COSTEIROS: O CASO DO PARQUE DAS DUNAS DO MUNICÍPIO DE BARRA DOS CoQueIros - SE
}

\author{
Nara Vieira de Souza ${ }^{1}$, Roberto Wagner Xavier de Souza ${ }^{1,}$ Maria José Nascimento Soares ${ }^{2}$, \\ Daniela Teodoro Sampaio ${ }^{3}$
}

\author{
${ }^{1}$ Doutorando do Programa de Pós Graduação em Desenvolvimento e Meio Ambiente - PRODEMA. Universidade Federal de Sergipe. Aracaju, Sergipe, Brasil. \\ ${ }^{2}$ Docente do Departamento de Educação da Universidade Federal de Sergipe \\ ${ }^{3}$ Pos-doc e Professora Visitante do Programa de Pós-Graduação em Desenvolvimento e Meio Ambiente - PRODEMA / UFS \\ *Autorpara correspondência:nvdss@yahoo.com.br
}

Recebido em 12 de outubro de 2015. Aceito em 9 de junho de 2016. Publicado em 31 de março de 2017.

REsumo - Este trabalho analisa a intersecção de valores envoltos em um contexto sistêmico e interdisciplinar na gestão de conflitos socioambientais, tomando como área de estudo o litoral, espaço complexo, multifuncional e cenário de conflitos variados. Com propósito de relacionar governança e um novo enfoque para a solidariedade ambiental, nesse estudo o objeto de análise é o Polígono das Dunas, localizado no município Barra dos Coqueiros - SE. O Polígono tem apresentado cenário conflituoso entre residentes, gestão pública e a utilização dos recursos naturais ao longo do trajeto litorâneo do município. Muitas pesquisas foram desenvolvidas para compreender os conflitos desencadeados pelo uso dos recursos naturais no ecossistema litorâneo, como também tem contribuído para a construção de modelos mitigadores da degradação ambiental. O presente artigo objetiva demonstrar a relação entre a solidariedade e governança ambientais visando uma melhor gestão na área do polígono, alcançando maior efetividade das políticas públicas socioambientais.

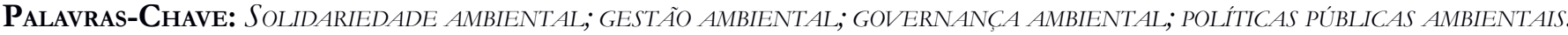

ENVIRONMENTAL SOLIDARITY AND ENVIRONMENTAL GOVERNANCE IN THE MANAGEMENT OF COASTAL ENVIRONMENTS: THE case of the Parque das Dunas in the municipality of Barra dos Coqueiros in Sergipe State, Brazil

Abstract - This study analyzes the intersection of values in a systemic and interdisciplinary context in the management of socio-environmental conflicts, considering the coast as the study area, which is a complex and multifunctional space, consisting of a scenario of various conflicts. With the purpose of relating governance to a new approach on environmental solidarity, the object of analysis, in this study, is the Polígono das Dunas (Dunes Polygon), located in the municipality of Barra dos Coqueiros, Sergipe State, Brazil. In this Polygon there have been conflicts between residents, public management and use of natural resources along the coast of the municipality. Many studies have been carried out to understand the conflicts triggered by the use of natural resources in the coastal ecosystem, contributing to the development of models to mitigate the environmental degradation. This study aims to demonstrate the relationship between environmental solidarity and environmental governance to make possible a better management in the Polygon, achieving greater effectiveness in the social and environmental public policies.

KEYWORDS: ENVIRONMENTAL SOLIDARITY; ENVIRONMENTAL MANAGEMENT; ENVIRONMENTAL GOVERNANCE; ENVIRONMENTAL PUBLIC POLICIES.

SOLIDARIDAD Y GOBERNANZA AMBIENTAL EN LA GESTIÓN DE AMBIENTES COSTEROS: EL CASO DEL PARQUE DE LAS DUNAS EN 
el municipio de Barra dos Coqueiros, Estado de Sergipe, Brasil

RESUmen - Este estudio examina la intersección de los valores envueltos en un contexto sistémico e interdisciplinario en la gestión de conflictos socio-ambientales, tomando como área de estudio el litoral, un espacio complejo, multifuncional y escenario de diversos conflictos. Con el propósito de relacionar la gobernanza con un nuevo enfoque acerca de la solidaridad ambiental, el objeto de análisis en este estudio es el Polígono de las Dunas, en el municipio de Barra dos Coqueiros, Sergipe, Brasil. En este polígono han ocurrido conflictos entre los residentes, la gestión pública y el uso de los recursos naturales a lo largo del litoral del municipio. Muchas investigaciones se han desarrollado para entender los conflictos provocados por el uso de los recursos naturales en el ecosistema costero, contribuyendo a la construcción de modelos para mitigar la degradación del medio ambiente. El objetivo de este estudio fue demostrar la relación entre la solidaridad y gobernanza ambiental, buscando una mejor gestión en el área del polígono, alcanzando una mayor eficacia de las políticas públicas ambientales.

Palabras Clave: Solidaridad AMBIENTAL; GESTIÓN AMBIENTAL; GOBERNANZA AMBIENTAL; POLÍtICAS PÚBLICAS AMBIENTALES.

\section{INTRODUÇÃO}

O contexto desse artigo envolve litoral, ecossistema costeiro e gestão de ambientes costeiros numa proposta de relacionar uma releitura do princípio da solidariedade e governança. Tendo em vista o litoral ser por excelência um espaço complexo, multifuncional e cenário de conflitos variados (Vilar e Santos 2011), torna-se um exemplo relevante para o estudo da intersecção de valores envoltos em um contexto sistêmico e interdisciplinar na gestão de conflitos socioambientais.

Vilar (2011) apresenta que os três elementos que mais chamam atenção nas modificações territoriais e paisagísticas nos domínios ambientais do litoral sergipano são: a urbanização, a industrialização e o uso turístico do território.

O caráter intensivo da apropriação do espaço litorâneo, priorizando o aspecto econômico, tem instigado pesquisas que objetivam, de maneira geral, compreender o cerne de conflitos ambientais acerca do uso dos recursos naturais nesse ecossistema e contribuir na busca do entendimento e na construção de modelos mitigadores da degradação ambiental.

Os conflitos socioambientais giram em torno de objetos de disputas, que envolvem múltiplos atores, nos âmbitos sociais, econômicos, políticos, culturais e territoriais. O objeto, em análise, é o Polígono ${ }^{1}$ das Dunas, localizado entre os municípios de Barra dos Coqueiros e Santo Amaro das Brotas, no Estado de Sergipe, que tem sido alvo de conflitos entre poder público municipal, órgãos ambientais estaduais e população envolvida em grilagem de terras.

O município de Barra dos Coqueiros, distante a $1 \mathrm{~km}$ da capital do estado, faz divisa ao norte com os municípios de Pirambu e Santo Amaro das Brotas, a oeste com Aracaju e a leste com oceano atlântico. Com uma população de 29.059 habitantes, o município possui uma área de

aproximadamente $91 \mathrm{~km}^{2}$, distribuídas entre a sua sede e mais 6 (seis) povoados (IBGE Cidades 2013).

Em 17 de dezembro de 2008, após Zoneamento do Polígono, a população dos referidos municípios, por

1 Euclides de Alexandria, o 'pai da geometria', definiu polígonos como sendo uma figura plana, fechada por segmentos de retas. Uma das formas de aplicação dos polígonos na geografia refere-se ao georreferenciamento de propriedades. Dentre as inúmeras aplicabilidades do polígono na Geografia, especificamente para o geoprocessamento, podemos citar os diagnósticos ambientais, assim como também a delimitação de áreas de preservação permanente, dentre outras áreas de interesses específico. Disponível em http:// brasilescola.uol.com.br/matematica/classificacao-dos-poligonos.htm $>$ https://www.ufpe.br/cgtg/SIMGEOII CD/Organizado/ cad/169.pdf $>$ Acessado em 06 de junho de 2016. 
meio de consulta pública, decidiu acatar a proposta de criação do Parque Estadual das Dunas. Por se tratar de uma área que abrange dois municípios a criação de Unidade de Conservação (UC) depende de ato legal a ser emitido pelo Estado de Sergipe ${ }^{2}$.

A relevância de estudos na referida área é demonstrada pela diversidade de recursos naturais no espaço e por constantes irregularidades de edificações construídas nessa área, conforme os estudos de Santos (2011) e Rocha (2007) apontam, que até então é um polígono, onde os atores estatais anseiam caracterizar como uma Área de Proteção Permanente - APP3.

Atualmente a área total do Polígono das Dunas tem uma extensão em torno de 3.000 hectares. Conforme Santos (2011), o polígono abrange ainda o Aquífero Marituba, que é considerado o segundo maior aquífero do estado de Sergipe, manancial formado por águas subterrâneas de boa qualidade, com uma reserva que poderá produzir até 300 mil litros por hora em um único poço, quantidade suficiente para atender uma população de aproximadamente 25 mil pessoas, além do rio Pomonga. Segundo o Relatório 18\2015 da Prefeitura Municipal de Barra dos Coqueiros-SE, o polígono também possui catalogada uma relação de 112 aves endêmicas com duas espécies ameaçadas de extinção.

A maior parte do polígono se localiza nos limites territoriais do município de Barra dos Coqueiros e este ente federado, desde a construção em 2006 da ponte Aracaju-Barra, ligando a capital ao município, tornou-se rota turística capaz de interligar a maior parte do litoral sergipano. A região passa por forte processo de especulação imobiliária. Em virtude disso, inúmeros conflitos sociais, fundiários e ambientais estão se desencadeando, por parte da iniciativa privada, organizações sociais, da comunidade local e entre as instâncias públicas.

Partindo dessa premissa, os estudos realizados no município de Barra dos Coqueiros, citados a seguir, têm apresentado cenário conflituoso entre residentes e gestão pública Há fortes dicotomias desde o uso e ocupação do espaço natural até a efetividade de políticas públicas fiscalizadoras e sociais ao longo do trajeto litorâneo do município.

Estudo sobre essa área costeira, como o de Santos (2011), aborda áreas de dunas do Jatobá, povoado do Município de Barra dos Coqueiros, o qual verificou que os conflitos socioambientais configuram-se pelos processos de uso e de posse dos recursos bióticos e abióticos, propondo políticas de gestão ambiental que envolvam a população e que atendam os critérios da Lei 9.985/2000, que instituiu o Sistema Nacional de Unidades de Conservação (SNUC).

Santana (2012) pesquisou as "geotecnologias" aplicadas ao estudo da expansão urbana na Barra dos Coqueiros, ressaltando a importância do estudo face ao aumento populacional em virtude da nova dinâmica de infraestrutura financiada pelo poder público e como tais medidas ocasionaram conflitos múltiplos de ordem

2 De acordo com o inciso I do art. $4^{\circ}$ da lei 12.651/2012, Código Florestal, a área de preservação permanente, onde não pode haver construções é de trinta metros para o curso d'água com menos de dez metros de largura, caso do rio Mangaba. Apesar da legislação, os pareceres técnicos da ADEMA (Administração Estadual do Meio Ambiente - Autarquia Estadual criada pela Lei $\mathrm{n}^{\circ}$ 2.181, de 12 de outubro de 1978, que veio ser alterada pela Lei 5.057, de 07 de novembro de 2003, e que possibilita a execução das políticas estaduais relativas ao meio ambiente) sobre o condomínio residencial Portal da Barra indicavam "afastamento mínimo de 30 metros do Rio Mangaba, podendo, todavia, tal faixa ser ocupada por piscina, quadra, passeios, que não concorram para a total impermeabilização do solo".

3 As Áreas de Preservação Permanente (APPs) são espaços territoriais especialmente protegidos de acordo com o disposto no inciso III, $\int 1^{\circ}$, do art. 225 da Constituição Federal. O Código Florestal traz um detalhamento preciso das Áreas de Preservação Permanente (aplicável a áreas rurais e urbanas), da Reserva Legal (aplicável às áreas rurais) além de definir outros espaços de uso limitado. As APPs são aquelas áreas protegidas nos termos dos arts. $4^{\circ}$ ao $9^{\circ}$ do Código Florestal. O conceito legal de APP relaciona tais áreas, independente da cobertura vegetal, com a função ambiental de preservar os recursos hídricos, a paisagem, a estabilidade geológica, a biodiversidade, o fluxo gênico de fauna e flora, proteger o solo e assegurar o bem-estar das populações humanas. Como se vê, as APPs não têm apenas a função de preservar a vegetação ou a biodiversidade, mas uma função ambiental muito mais abrangente, voltada, em última instância, a proteger espaços de relevante importância para a conservação da qualidade ambiental como a estabilidade geológica, a proteção do solo e assim assegurar o bem estar das populações humanas. 
territorial. Ele propõe um sistema de informações geográficas para monitoramento de mudanças contínuas na expansão urbana, a fim de cartografar tecnicamente usos e conflitos desse espaço.

Rocha (2007), analisando a gestão de resíduos sólidos em Barra dos Coqueiros, identificou que seu tratamento ocorre em um sistema de disposição incorreto, ocasionando prejuízos a todo ambiente do município. Como recomendação, indica um plano integrado de gerenciamento para resíduos sólidos, estudo para implantação de aterro sanitário e a incorporação ao plano diretor local de projetos de coletas seletivas e de reciclagem que minimizem danos que atingirão toda zona costeira.

Como pode ser observado as alterações intrínsecas no município têm motivado pesquisas, as quais analisam as situações que vêm agredindo o ecossistema costeiro e refletindo na população residente de toda zona litorânea. O presente artigo tende a concatenar as informações desses estudos e do relatório ambiental e de análise da prefeitura de Barra dos Coqueiros, paralelamente às modificações impostas através do processo de urbanização na área do Polígono das Dunas, entre os municípios de Barra dos Coqueiros e Santo Amaro, trazendo contribuições para uma melhor adoção de políticas e gestão pautadas em elementos da governança e subsidiado por uma releitura do princípio da solidariedade ambiental.

O objetivo do presente artigo é demonstrar a relação entre a solidariedade e governança ambientais de forma que se venha a subsidiar uma melhor gestão na área do polígono das Dunas, buscando uma maior efetividade das políticas públicas, em especial, as ambientais, ali desenvolvidas.

Assim, tendo em vista as situações expostas, orientam essa investigação as seguintes questões de pesquisa:

- Quais os caracteres interseccionais entre a governança e a solidariedade ambientais?

- Como proporcionar maior eficácia à gestão ambiental de um ecossistema extremamente vulnerável (costeiro) atrelando à ideia de solidariedade ambiental?

- Quais as ferramentas que a governança ambiental propicia para a análise da gestão ambiental, de ecossistemas costeiros?

- O artigo está dividido em três partes. Na primeira, o eixo da discussão gira em torno de ambiente, solidariedade e governança ambiental. Na segunda parte é feita uma contextualização da localidade e avanços e desafios na relação solidariedade e governança para uma gestão ambiental efetiva. Por último, são apresentadas propostas e considerações finais.

\section{Solidariedade e governança ambientais}

Um novo senso comum, pós-ciência, denota um Novo Senso Ambiental. Após passar pelo crivo da ciência, o senso ambiental objetiva legitimar o conhecimento desde o viés e configuração de uma ciência normal (manuais), à difusão, aplicação social e a preservação de valores e bens materiais ambientais.

A expressão cotidiana, senso comum ou bom senso, é manifesta na questão ambiental. $O$ paradigma dominante visualiza a natureza como fator resultante ou consequência a ser tratada sem alterar os motivos e as fontes dos problemas que a provocam. O conhecimento científico deverá se traduzir em um conhecimento concreto, massificado, difundido que não terá apenas bases costumeiras ou de tradição, mas bases científicas sólidas e comprometidas com a realidade social pautada em valores culturais, políticos, éticos e não excludentes (Souza, 2013).

Souza (2013) destaca que a visão mercadológica da ciência ou a azáfama da posse, da propriedade, do uso e 
do aproveitamento dos recursos caracteriza a natureza como meio, sem conceber que ela representa mais que o meio ambiente. Ela instaura o princípio ou os princípios, cujo fim colimado é a manutenção, regeneração, defesa e a propulsão da vida.

A desumanização da natureza e a desnaturalização do homem, provocada pela distinção ontológica entre ambos e entre as ciências sociais e naturais propiciaram as condições para que o ser humano se utilizasse de poder arbitrário, ético e politicamente neutro para com ela (Santos, 2003).

Ora posto, a solidariedade restou relegada ao plano da responsabilização e não à integração sistêmica. É no âmago desta crise que se projeta a reintegração da natureza no homem enquanto objetivo de conhecimento. A exploração científica da natureza está atrelada à exploração do homem pelo homem. Ferry (2009) vê no humanismo cartesiano a doutrina que mais longe chegou na desvalorização da Natureza em geral.

A realidade social não pode ser desvinculada da questão ambiental. A natureza perfaz além do direito e da conjectura social, o prenuncio da atividade científica. Ao não passar pelo julgo da falseabilidade ou havendo dificuldade em empreender o mesmo, seguindo Popper (2007), a ciência não se revestirá de subsídios reais que possam abalizá-la.

A consolidação de um novo valor perpassa pela identidade, percepção, sensibilidade e possibilidade de que se gerem referenciais plausíveis e executáveis. A concepção integrativa do ambiente decorre da participação cidadã e da possibilidade de reinserção das ciências. Desse modo, poder-se-á responder às demandas sociais e ambientais atuais, suscitadas pela modernidade (pós-modernidade).

A relação entre o ser humano e a natureza se faz no tempo e no espaço, porém natureza rompe com as barreiras geográficas e de gerações. A tradição, segundo Gadamer (2001), é o conduto que faz fluir os elementos da vida social pelo passado, presente e futuro.

Para Gadamer (2001) a interpretação e posteriormente a compreensão derivam dos referenciais axiológicos trazidos pela tradição. São como acordos profundos que se traduzem em uma forma de solidariedade; uma plataforma implícita e essencial para o entendimento e o agregar de valores. Uma relação de responsabilidade entre indivíduos com interesse comum.

Capra (2006) alude que as comunidades ecológicas se conjugam em uma rede de interdependências, que requer um sistema eticamente novo. Essa rede denota um certo grau de solidariedade e responsabilidade pelos que detém a racionalidade e capacidade de fato.

Os princípios trazem uma carga de valores e interdependências. Para Souza (2013) toda interdependência presume um cerne de solidariedade, pois conduz a um estado de complementaridade, não exclusiva, mas necessária. A solidariedade traz uma agenda de aspirações políticas, éticas, sociais e ambientais que se deslindam no tempo e espaço que as propicie.

Gadamer (2001) compreende que se faz providente a conscientização de solidariedades, pois elas superam as falhas do comunicar. Esse comunicar é ponto chave na condução de diretrizes de governança.

Nesse caminhar de sensibilizações de solidariedades, a solidariedade ambiental intergeracional é princípio que visa estender abrangência dos valores que lhe compõem vindo a subsidiar e embasar de forma finalística, projetos, normas, decisões, atos e políticas públicas ambientais.

No que confere à Governança, primordial a contextualização inicial, referenciando assim estudos de Araújo (et al. 2015) diz que o termo Governance surgiu de reflexões conduzidas principalmente pelo Banco Mundial, com objetivo de obter um Estado eficiente. Esse autor enfatiza ainda, que inicialmente, em nível global, governança 
era vista primeira como sendo apenas relações intergovernamentais, contudo atualmente a governança envolve organizações não governamentais, movimentos de cidadãos, corporações multinacionais e o mercado de capitais global.

O uso do termo "governança" reflete o deslocamento nas áreas de ciências sociais e de políticas públicas de abordagens focadas no conceito de governo para um conceito mais abrangente de governança que incorpora os atores não estatais. Para Delmas \& Young (2009) a Governança é uma função social centrada no esforço de levar a sociedade ou grupos sociais de uma situação coletivamente indesejada para uma realidade socialmente desejada.

Já a Cominssion on Global Governance (1995) define Governança “(...) como a soma das várias maneiras de indivíduos e instituições, públicas e privadas administrarem seus assuntos comuns”.

Outros autores consideram governança como uma ferramenta, no caso de Fonseca \& Bursztyn (2009) estes enfatizam ser essencial a governança, como relevante para execução de investimentos responsáveis. Nesse aspecto, os governos podem utilizar da governança para exercerem poder, para domínio da lei, transparência, ou seja, utilizar essa ferramenta como mecanismo correlato para "accoutability” pública unindo à participação cidadão.

Essa participação ampliada auxilia na construção de modelos de gestão, atualmente intitulada como Governança Ambiental, que segundo Jacobi \& Sinisgalli (2012) vem a intensificar a participação em todos os processos, o que requer envolvimento ativo de todas as partes interessadas (atores) em agendas pautadas pela busca de cooperação e consenso.

Como um acordo implícito e que se transfere pela tradição, ou ainda pela herança material, o conteúdo manifesto no art. $225^{4}$ da Constituição Federal da República Federativa do Brasil, antes de tratar das futuras gerações, confere a (co) responsabilidade da coletividade e do poder público na defesa do meio ambiente para as futuras gerações. No entanto, o que se resguarda das gerações ancestrais para as presentes e gerações vindouras é uma incógnita que a solidariedade ambiental intergeracional tende a preencher, sem descaracterizar o comprometimento ou a responsabilização.

Souza (2013) alude que o comprometimento se dirige aos efeitos, destacadamente aqueles deletérios ao meio ambiente, pois esses podem afetar de forma direta o território, a base do próprio Estado, o qual qualificou e corporificou no âmbito de sua Constituição à tutela da natureza. A responsabilização prevê as sanções ou consequências sócio-jurídicas que suscitarão resposta imediata da coletividade ou do Estado por intermédio dos atos de seus Poderes.

A formação cultural, histórica e política é reflexo das relações estabelecidas por um determinado povo. A base física e estrutural dessas relações é o território, o ambiente em que o povo constitui laços de identidade e reafirmação de valores. Os valores devem se dirigir a uma determinada finalidade. O reconhecimento de deveres fundamentais denota o liame existente entre a cultura e a natureza, especialmente se eles perduram no tempo.

A solidariedade ambiental propicia a melhor articulação dos atores envolvidos com a temática ambiental: atores estatais, não-estatais e diversos segmentos que participam da formulação e implementação de políticas públicas. Esse princípio tende a debelar a prevalência de uma visão instrumental, ao enfatizar o envolvimento ativo, da Sociedade Civil e dos poderes constituídos, juntamente com o Senso Ambiental apregoado por Souza (2013)

4 Art. 225. Todos têm direito ao meio ambiente ecologicamente equilibrado, bem de uso comum do povo e essencial à sadia qualidade de vida, impondo-se ao Poder Público e à coletividade o dever de defendê-lo e preservá- lo para as presentes e futuras gerações. 
A governança ambiental pressupõe uma dimensão de compartilhamento baseada na participação ampliada, na transformação das formas de governo e regulação que transcende as tradicionais hierarquias do Estado e dos sistemas de mercado. Anseia por um paradigma ou princípios que apresentem proposta teleológica e concretista de como o Estado, os mercados e a Sociedade Civil se alinham como parceiros em uma mesma lógica, sem desconsiderar as dicotomias existentes. Uma proposta que revigore as acepções e significado da natureza, sem olvidar dos avanços tecnológicos e dos princípios básicos do desenvolvimento sustentável.

A releitura da solidariedade ambiental suscita uma postura que tenha por base uma hermenêutica concretista. A hermenêutica constitucional concretista proposta por Peter Härbele (1997) suscita um modelo de interpretação menos ortodoxa e executada não somente por uma sociedade fechada, daqueles que lidam diretamente com a constituição e as normas. Ao invés disso, traz a noção de sociedade aberta dos interpretes da constituição.

Nesse contexto, faz-se preciso o elo entre as bases axiológicas do princípio da solidariedade ambiental intergeracional, que traz no seu cerne o caráter de responsabilidade e comprometimento da coletividade e do Estado como corresponsáveis pela manutenção do meio ambiente ecologicamente equilibrado para a sadia qualidade de vida, com uma releitura desse princípio.

A releitura estabeleceria que a responsabilidade vai além da responsabilização, mas pressupõe um ativismo e protagonismo daqueles a que o direito e o dever se dirigem, desde o caráter formal e programático da norma até os efeitos que ela produz, mas também denota a outorga da legitima, necessária e premente participação. Essa participação com vistas a propiciar interpretação, aplicação e articulação integrada dos atores sociais, pois eles detém de forma concreta, autoridade que lhes foi cediça pela tradição e relação direta com os bens socioambientais, como também autoridade e propriedade diante da relação e elo geracional, como herança imaterial.

Governança e Gestão Ambientais: Articulação e Consenso

A Governança promove o pluralismo político (McFarland 2007), com o objetivo de ocasionar eficiência e transparência nas escolhas e decisões públicas, de forma a inserir os atores sociais e processos. Esses atores são formados por indivíduos. O conjunto de indivíduos com características semelhantes formam uma comunidade. As comunidades integram a sociedade. A sociedade tem como principal característica a diversidade e a pluralidade, as quais se traduzem em diferenciação social.

Como proposta para um consenso entre Governança e Gestão ambientais, a articulação tem papel sine qua non em todo processo, já que possuem diferenças em suas bases conceituais. A gestão é a forma de execução, os métodos, as diretrizes, as metas. A governança é mais do que a execução, mais que um planejamento, porque passa por acordos, por uma participação equitativa de diversos grupos sociais num propósito de fortalecer ou de fazer funcionar as políticas públicas.

Em face da diferença entre gestão e governança, pelos temas que envolvem esse estudo, elegemos a gestão da coisa pública como referência de análise da gestão em ecossistemas costeiros.

A gestão da coisa pública perpassa pelo trato com as consequências advindas da modernidade, sem deslindar-se das relações e compromissos assumidos, ainda que tacitamente, no passado. Estabelecer deveres fundamentais de cunho transnacional, com as pessoas da mesma geração, das gerações vindouras e para com a 
Natureza como um todo, reescreve o diálogo intercultural, atualiza e revigora a tradição e redireciona os atores sociais.

No entanto, a Gestão Ambiental é um processo complexo e sistêmico que se dirige aos bens ambientais, que representa uma nova concepção acerca da classificação do patrimônio, pois se dirige a bens materiais e imateriais. Para a consecução eficaz, efetiva e eficiente a implementação de processos de gestão ambiental pressupõe a concatenação de políticas públicas, que gerem a articulação de atores através de diretrizes de governança ambiental.

A articulação dos interesses, anseios e condições, no âmbito da comunidade necessita de recursos em comum. Esses interesses podem ser: materiais ou ideais. Os materiais incluem o necessário à sobrevivência e os bens de desejo e posse, tais como propriedades, terras, dinheiro, entre outros. Os ideais se dirigem ao desenvolvimento cultural, intelectual, religioso, político; enfim às diversas ideologias. Assim, os interesses podem ser objetivos, ao se dirigirem às vontades e anseios de um grupo; ou ainda subjetivos, ao se ligarem aos interesses de um individuo, ainda que esses sejam compartilhados por outros (Rua, 2009).

Nesse contexto surgem as competições e conflitos, de origem ideológica ou para suplantar diferenças materiais. Um dos mecanismos de dirimir conflitos é a política.

Rua (1998) esclarece que a Política busca o consenso. Essa consiste no conjunto de procedimentos formais e informais que expressam relações de poder e que se destinam à resolução pacífica dos conflitos quanto a bens públicos. Conforme Araújo (et al. 2015), governança também pode ser tida como uma forma de caracterizar e promover políticas ambientais e de desenvolvimento. Eis o elo axiológico entre a governança e as políticas públicas ambientais.

A Política Pública para ser desencadeada precisa de uma lei, norma ou regulamento que a legitime. Deve provir de um conjunto de procedimentos oriundos do Estado, para depois desembocar em um planejamento. Esse é integrado por diversas ações estrategicamente selecionadas que culminarão no implemento das decisões a serem tomadas.

As decisões são o proferir de atos administrativos e de gestão obtidos após a confrontação das múltiplas preferências de diferentes atores, as condições materiais exequíveis, a observância dos limites legais e a legitimidade proveniente da participação dos representantes do Estado, da sociedade civil e da iniciativa privada.

A decisão tende a ser interdisciplinar e está intrinsecamente relacionada com o grau de sensibilização dos administrados e as repercussões sobre os bens públicos em questão.

Os atos de Gestão Ambiental, para serem implementados de forma efetiva, necessitam de planejamento que contemple a tríade: meio-homem-sociedade. Segundo Santos (2004), o planejamento ambiental pauta-se na integração e interação dos sistemas que compõem o ambiente, de forma que se estabeleçam as relações entre os sistemas ecológicos, os processos sociais, as necessidades sócio-culturais, atividades e interesses econômicos mantendo-se a máxima integridade possível dos elementos componentes do meio ambiente.

Como definição legal, de acordo com a Política Nacional do Meio Ambiente em seu inciso I do art. $3^{\circ}$ da lei 6.938/1981, ambiente é conceituado, como “[...] conjunto de condições, leis, influências e interações de ordem física, química e biológica, que permite, abriga e rege a vida em todas as suas formas” (Brasil 1981).

Outros conceitos são apresentados como, o conjunto, em um dado momento, dos agentes físicos, químicos, biológicos e dos fatores sociais suscetíveis de terem um efeito direto ou indireto, imediato ou a termo, sobre os seres vivos e as atividades humanas (Poutrel e Wasserman 1977); ou ainda, conjunto de todos os fatores físicos, 
químicos, biológicos e socioeconômicos que atuam sobre um indivíduo, uma população ou uma comunidade (Interim Mekong Committee 1982).

Ambiente, como referencia Reigota (2002), é o lugar determinado ou percebido, cujos elementos naturais e sociais se relacionam e interagem de forma a implicar nos processos culturais, tecnológicos e históricos, alterando o meio natural e o construído.

As representações sociais e suas modificações no tempo interferem quando se trabalha o tema ambiente (Sauvé 1996; Sauvé et al. 2000). Assim, pode-se falar em meio natural construído, o qual é estabelecido por representações sociais de um determinado grupo que evolui no tempo e se modifica a partir das relações estabelecidas.

Como na gestão da coisa púbica, a gestão ambiental e a aplicação de políticas públicas ambientais necessitam agregar de forma sistêmica tradição, cultura e sensibilização dos grupos sociais, diretamente envoltos na peculiar relação com o seu meio. Nessa relação são caracterizados os bens imateriais dispostos, os quais são de difícil e controversa mensuração.

Os riscos a que estão sujeitos esses bens denotam e legitimam a necessidade de serem aplicados novos valores de uso e não-uso, que não podem ser negados. O agregar valores intrínsecos e de existência traduz como a prática e a apropriação do ambiente vai concretizar os atos de gestão e as políticas públicas ambientais a serem aplicadas.

A integração dos valores não visa desconstruir bases ou raízes culturais. Consequentemente essa é uma das vertentes do desenvolvimento sustentável, que depende das práticas dos atores (estatais e não-estatais) e do êxito de estratégias que possam fazer uma transição que redirecione o desenvolvimento sem olvidar da manutenção dos bens materiais e imateriais da natureza.

\section{O poligono das dunas (futuro ou pretenso Parque das Dunas)}

A área do Polígono das Dunas possui uma extensão de aproximadamente 3.000 hectares, localizada entre os municípios de Santo Amaro e Barra dos Coqueiros, no estado de Sergipe, Brasil, com maior parte instaurada no município de Barra dos Coqueiros, especificamente no Povoado Jatobá (SEMARH-Planta Baixa 2008).

Como já descrito anteriormente, o polígono possui fatores indispensáveis para instauração de um parque estadual, já que possui uma diversidade de recursos naturais que favorecem a permanência como UC. Quanto maior a área preservada, maior espaço para carregamento do aquífero e proteção ao habitat das espécies endêmicas de aves em toda sua área. Em toda a extensão do polígono, caso venha a ser formalizada, nos moldes da legislação ambiental, como unidade de conservação (Parque), não a descaracterizaria de seu potencial socioeconômico, pois seria uma área contígua ao uso humano.

A área destinada ao futuro "Parque Estadual das Dunas", após o cumprimento de todos os requisitos legais, carece ainda da consecução dos atos administrativos necessários à efetivação da criação da Área de Proteção Permanente-APP. A questão é dicotômica, pois uma vez superados os entraves administrativos e preenchidos os requisitos legais, há óbice de natureza política.

A região é representativa de ambientes costeiros, formada por restingas, manguezais e lagoas. Estudos realizados pela Secretaria Estadual de Meio Ambiente e Recursos Hídricos (SEMARH), excluíram da delimitação as áreas com ocupação humana, como a comunidade do povoado de Touro e mais dois loteamentos em áreas 
de praias. Essa medida teve como condão respeitar o direito de propriedade e os caracteres socioambientais, uma vez que essas propriedades não ocasionaram impacto ambiental negativo significativo para o (SEMARH, Consulta Pública 2008)

As áreas de dunas, localizadas pela parte do município de Barra dos Coqueiros-SE, tem sido alvo da ação de invasores (pessoas advindas do entorno e de outros municípios) que chegam a se utilizar de grilagem no local, o que denota a intenção de configurar um título de propriedade, o qual pode vir a reverter a natureza jurídica de bem ambiental ou ainda ocasionar uma desapropriação indevida gerando créditos e capital para os grileiros.

Nessas configurações, para efeito de descrição nesse tipo de invasão, o presente estudo não ignora a necessidade emergencial de um plano de intervenção social, elaborado por órgãos estatais, deste o ente municipal e o estadual. Os estudos já realizados na região acerca dos problemas ambientais e sociais existentes denotam a premente necessidade e a real situação dos que tem ocupado a área do polígono, especialmente, ao se analisar a problemática individual dos ocupantes.

Um dos exemplos das consequências desses conflitos é que desde a aprovação por parte das comunidades envolvidas, dos municípios que abrangem o polígono, até então, o Estado de Sergipe não proferiu o ato legal que formalizaria a criação da Unidade de Conservação Parque Estadual das Dunas. Um dos motivos é que a nova categorização enseja que não será possível haver exploração econômica direta ou imobiliária naquela região.

Recentemente, a Ouvidoria do município da Barra dos Coqueiros, através do ouvidor representante da prefeitura local, registrou em matérias de jornais televisivos constantemente a questão da ocupação indevida, exploração imobiliária e dos recursos naturais do polígono das Dunas, constando em Relatório ${ }^{5}$ com imagens das ocorrências, conforme visualizado na Figura 1.

Figura 1 - A) Paisagem da área de dunas, localizadas no polígono; B) Paisagem da área de dunas após a intervenção antrópica, com a ocupação indevida da área; C) Vias de acesso à área indevidamente ocupada, durante a fiscalização dos órgãos públicos (atores estatais) envolvidos; D) Placa da Associação de Moradores (atores não-estatais) afixada com o intuito de debelar a ocupação do polígono. Fonte: Prefeitura do Município de Barra dos Coqueiros-SE (Relatório de atividades n. 18/2015)
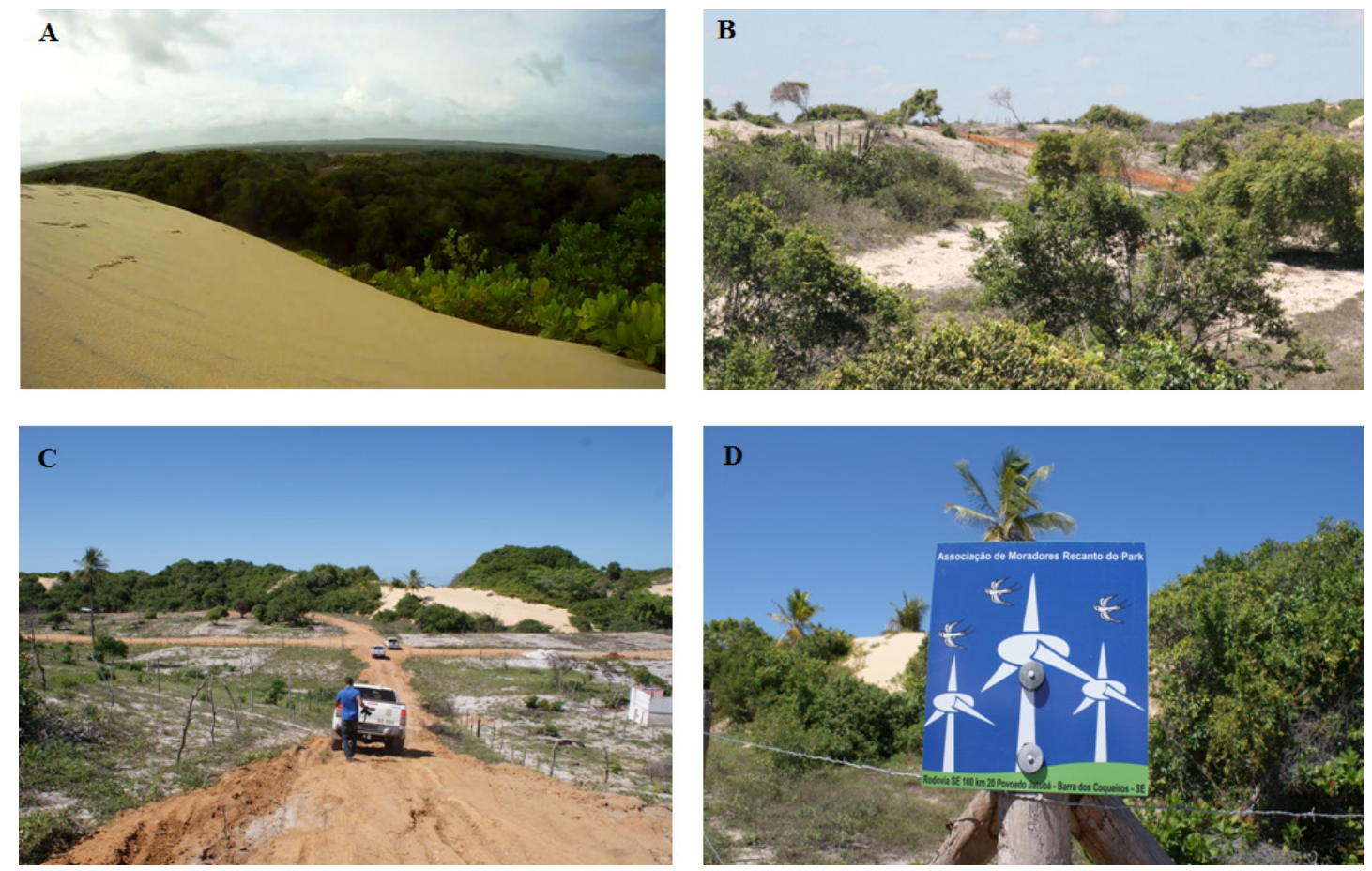

5 RELATÓRIO 18 \2015. Comissão Especial para Análise, Estudo, Fiscalização e Intervenções em Moradias e Construções nas APP's do Município de Barra dos Coqueiros-SE. Lei no 786/2014. De 30 de julho de 2015. Prefeitura Municipal de Barra dos Coqueiros-SE 
Esse estudo apresenta algumas imagens de fotografias que foram veiculadas em matérias de jornais televisivos, por meio de declarações fornecidas pelo poder público municipal da Barra dos Coqueiros-SE, informando à sociedade como se encontra a atual situação do processo e procedimentos que registram a violação cada vez mais agravante em invasões nas áreas de Dunas, como também a venda de lotes da área, desvirtuando e ferindo a legislação ambiental.

O mapa e o recorte abaixo (Figura 2) nos permitem apresentar áreas de abrangência do polígono já delimitado para futuro Parque Estadual das Dunas. Na figura menor, estão demarcados os municípios localizados no litoral de Sergipe, com ênfase para a Barra dos Coqueiros (lócus desse estudo) com seus respectivos entorno territoriais.

Deve-se registrar que a Lei 6.766 de 19 de dezembro de 1979 que enumera as responsabilidades sobre parcelamento do solo urbano para fins urbanos, no Capítulo IX Artigo 50 inciso III, tipifica o que nesses casos constitui crime contra administração pública ${ }^{6}$. Assim, a existência de crime cometido por parte de moradores ou visitantes do entorno do polígono, se constatado por órgãos competentes e autuados, poderão ser punidos com pena de reclusão ou detenção. Isso enseja o grau e a potencialidade ofensiva perante o bem ambiental.

Identificadas as finalidades, sejam de cunho econômico (apenas com interesses imobiliários) ou de cunho social (carência de moradia), faz-se necessário tratamento jurídico diferenciado para ambos os casos, seguindo o propósito e escopo da justiça ambiental.

Figura 2 - Mapa da região do polígono (futuro parque) situado no litoral do Estado de Sergipe.
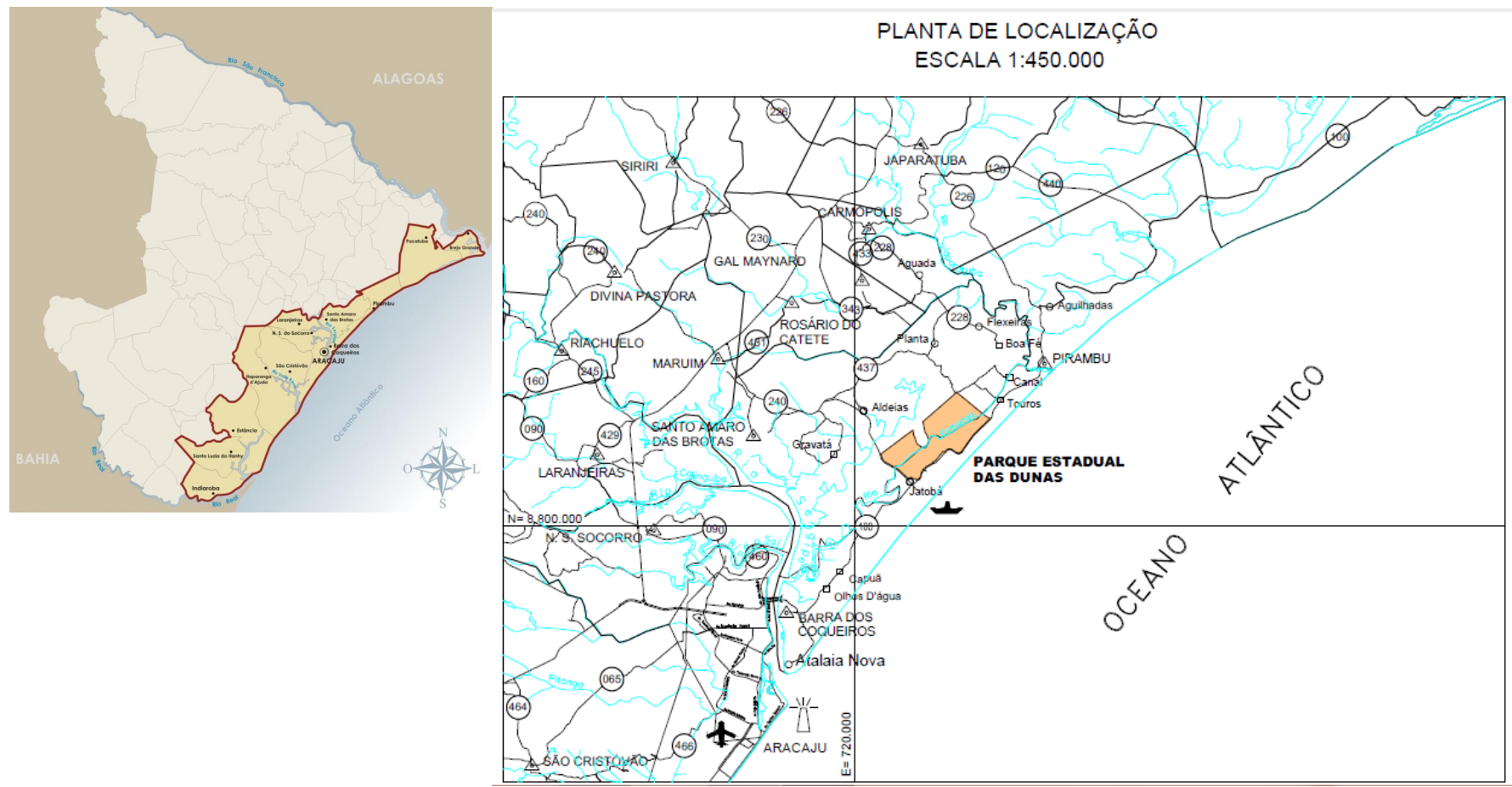

Fonte: SEMARH/SE

É oportuno observar duas questões com a instauração do parque nessa área em estudo. A primeira, caso

6 O inciso III do art. 50 da Lei 6.766: Constitui Crime contra Administração Pública fazer ou veicular em proposta, contrato, prospecto ou comunicação ao público ou a interessados, afirmação falsa sobre a legalidade de loteamento ou desmembramento do solo para fins urbanos, ou ocultar fraudulentamente fato a ele relativo. Pena: Reclusão, de 1 (um) a 4 (quatro) anos, e multa de 5 (cinco) a 50 (cinqüenta) vezes o maior salário mínimo vigente no País. 
o parque seja formalizado, o aquífero não poderá ter utilização econômica, debelando a ação humana de forma que venha a ocasionar impactos para o uso da água como bem comum. A segunda, com a criação do parque, tanto o aquífero como as espécies de aves, inclusive as ameaçadas de extinção, terão maior amparo perante a intervenção antrópica, muitas das vezes, danosa.

Contudo, diante do impasse para a formalização efetiva da área do polígono em parque estadual, o Poder Público Municipal da Barra dos Coqueiros como forma de debelar as invasões tem desenvolvido atividades para conter as invasões no Município de Barra dos Coqueiros, bem como desocupar aquelas já existentes e que constantemente são alvo de denúncias. Essa medida tem por objetivo impedir que as invasões sejam legitimadas, pois como não houve a categorização da área como UC, todas as propriedades que ali se instalarem podem ser objeto de contenda judicial, sob a alegação de que a propriedade foi estabelecida antes da classificação como Área de Proteção Permanente, a exemplo do que ocorre em algumas regiões do país, por meio de um processo conhecido como grilagem.

\section{CONSIDERAÇõES FINAIS}

A implantação do parque é de extrema importância, por fatores preponderantes para a sustentabilidade socioambiental na localidade, em especial o aquífero, o qual é um recurso recarregável. Com a cobertura do solo e com a implantação do parque haveria defesa para a confluência, em um raio limitado apenas de $1 \mathrm{~km}$, de três ecossistemas naturais existentes: restinga, mangue e lagoas.

Portanto, o processo de sensibilização, quiçá o de percepção, da natureza como parceira, propiciará compreensão e integração diante dos elementos, recursos e seres em interação sistêmica na natureza. É condição si ne qua non extinguir costumes ou práticas que tendem a fenecer o ecossistema. O ser humano deve se sentir coadjuvante nesse cenário da natureza, para que seja raro ou exterminado a constância da conturbação - ocupação do solo indevidamente.

A solidariedade se registra na compatibilização dos atores quanto ao uso de toda área preservada, principalmente no uso adequado e conservação do aquífero. Não se pode olvidar da sensibilização para problemas sociais existentes, quanto à compensação de construções irregulares (nas áreas invadidas), sendo devidamente identificada a carência das pessoas e exclusão de aproveitamento por parte da especulação imobiliária crescente na região. Há uma gama de dicotomias que se manifestam desde a formalização tardia e morosa por parte dos órgãos públicos e a pouca articulação e integração social de grupos direta e indiretamente envolvidos com a conservação do polígono.

Toda transformação socioespacial requer planejamento capaz de consolidar eficazmente e dar encaminhamentos resolutivos aos impactos, sejam eles categorizados como socioeconômicos ou socioambientais, resultantes de implantações adversas em comunidades.

$\mathrm{Na}$ localidade em estudo, constata-se que não há um sistema de gestão ambiental e nem ações integrativas das políticas públicas existentes no município.

A questão da intervenção sobre as ocupações no Polígono das Dunas, no município de Barra dos Coqueiros-SE, é de responsabilidade da ouvidoria municipal, executando ações, seja no âmbito jurídico, fiscal e na relação com a comunidade. Não há interação e comprometimento de secretarias afins, como meio ambiente, agricultura, assistência social, que promovam a coordenação de ações interventivas socioambientais. 
Salientamos que o fato da não efetivação do polígono como um parque, não se deve ao fato do local constituir apenas por diversidade florística, já que o mesmo possui reconhecimento de outros elementos naturais, como aquífero, várias espécies de aves e vegetação endêmica, ou seja, existem vários aspectos motivadores para se constituir um parque, categorizado como uma Unidade de Conservação- UC pelo SNUC. (Lei 9.9985, ano 2000)

Para analisar conflitos socioambientais é preciso compreender o papel dos atores sociais em uma localidade e no contexto que se inserem. Neste sentido, no referido município não existem atos que se denominem de governança ambiental. O que existem são elementos propícios para construção de uma política de governança pautada na resolução de conflitos e identificação de impactos socioambientais necessária para a implementação de medidas mitigadoras que possam equilibrar o nível e a quantidade de conflitos. Ressalte-se que não há como debelar a existência de todos os conflitos. Eles podem servir como indicadores necessários à reavaliação dos atos de gestão.

De posse das constantes denúncias intituladas "Invasões de terrenos na Barra dos Coqueiros, em Sergipe"; ou "Sobre os terrenos que estão sendo ocupados em área de preservação" a ouvidoria municipal tem se munido de comprovações sobre as violações ao Código Florestal ${ }^{7}$, e, assim solicita, constantemente, ao Ministério Público a demolição de edificações em área de proteção permanente frente à irregularidades com edificação na área do Polígono Parque das Dunas. Para isso precisa urgentemente da legitimidade e eficiência proporcionadas não somente pelos dados e técnicas à disposição, mas pela articulação dos atores envolvidos.

Desta forma, entendendo que a integração entre responsabilidade e responsabilização por parte de população, poder público municipal, entidades fiscalizadoras num propósito de conservação do recurso natural em estudo, resultarão em solidariedade e governança ambientais concretistas para formulação de políticas públicas ambientais correlatas com o cenário e localização dessa UC.

Para tal a solidariedade ambiental, em especial para a concretização de efeitos, suscita o estabelecimento e a tomada de decisões que contemplem uma matriz que tenha por base:

A massificação do conhecimento, classificação, caracterização, das formas legais e técnicas de uso e preservação ambientais.

A difusão da sensibilização ambiental (senso ambiental), de maneira que todos os integrantes de uma comunidade ou região concebam uma identidade não apenas com o meio em que vivem, mas também com as relações culturais, políticas e socioambientais que em determinado espaço e as que no decorrer das gerações são desenvolvidas.

O estímulo à participação (democracia ambiental) nos processos de estabelecimento de prioridades e diretrizes, a serem adotadas por todos os integrantes, respeitando-se a diversidade do uso e usufruto do meio e observando-se as respectivas responsabilidades e sanções (responsabilizações).

A prioridade na adoção de políticas públicas alinhadas aos processos de tomadas de decisão de matriz socioambiental, sem subtrair valores que agreguem a concepção de pertença e propriedade (tradição, autoridade e herança).

Como sugestões técnicas e para uma maior e melhor concatenação do ativismo político dos atores

$7 \quad$ O Código Florestal prevê faixas e parâmetros diferenciados para as distintas tipologias de APPs, de acordo com a característica de cada área a ser protegida. No caso das faixas mínimas a serem mantidas e preservadas nas margens dos cursos d'água (rio, nascente, vereda, lago ou lagoa), a norma considera não apenas a conservação da vegetação, mas também a característica e a largura do curso d'água, independente da região de localização, em área rural ou urbana.O Código Florestal (art. $2^{\circ}$ ) também estabelece proteção permanente para as bordas de tabuleiros ou chapadas, os topos de morro, montes, montanhas e serras e para as encostas com alta declividade, entre outras áreas de grande relevância ambiental. Art. $2^{\circ}$ Consideram-se de preservação permanente. 
governamentais e não governamentais, pode ser melhor operacionalizado o Cadastramento Ambiental, articulado por parte de pessoas interessadas na área (comunidades), culminando com um Programa de Recuperação de Áreas Degradadas - PRAD, para que além de institucionalizar os passivos ambientais, a sociedade civil tenha dados e subsídios técnicos de controle e acompanhamento.

O Estado de Sergipe possui um PRAD, elaborado com base na Instrução Normativa do IDAF $n^{\circ} 27-$ N/2007 e Instrução Normativa do IEMA n 17-N/2006 que institui um Termo de Referência com o objetivo de estabelecer critérios técnicos básicos e oferecer orientações para elaboração de Projetos de Reflorestamento e de Recuperação de Áreas Degradadas (PRADs) visando à restauração de ecossistemas. Aliar essa técnica com a matriz apresentada dinamizará e concretizará o estabelecimento de atos de gestão socioambientais profícuos, especialmente na área do futuro parque das dunas.

\section{Agradecimentos}

Manifesto nosso reconhecimento ao Programa de Desenvolvimento em Meio Ambiente de Sergipe PRODEMA-UFS pelo incentivo à publicação acadêmica fomentando produções científicas. Agradecemos ainda à todo empenho da orientação prestada pela Profa. Dra. Daniela Sampaio, que faz parte do Programa de Apoio ao Pós-Doutorado no Estado de Sergipe- Edital CAPES/ FAPITEC/SE N 11/2012, durante elaboração desse artigo de revisão bibliográfica, no que resultou em argumentos teóricos, fundamentados em análises contextualizadas com o lócus pesquisado.

\section{REFERÊNCIAS}

ARAÚJO, R.M. de; FERREIRA, L.F.; FEREIRA, D.D.M.; CAMINHA, R.G. 2015. Governança Ambiental: Análise da Produção Científica em Periódicos entre 2002 e 2014. UFBA-CSEAR: Salvador.

BECK, U. 2010. Sociedade de risco - rumo a uma outra modernidade. São Paulo: Editora 34.

BENJAMIN. A.H. V. Desapropriação, reserva florestal legal e áreas de preservação permanente Disponível em: http://daleth.cjf.jus.br/revista/numero3/artigo04.htm Acessado em 22 de abril de 2016.

BOBBIO, N. 2005. Estado, governo, sociedade: Para uma teoria geral da política. Tradução Marco Aurélio Nogueira. 12 ed. São Paulo: Paz e Terra.

BRASIL. Constituição da República Federativa do Brasil (de 05 de outubro de 1988) Disponível na Internet no site: <www.planalto.gov.br> acessado em 05 de novembro de 2015.

CANOTILHO, J. J.G.; LEITE, J. R. M. (Orgs.). 2010. Direito Constitucional Ambiental Brasileiro. 3 ed. São Paulo: Saraiva.

CAPRA, F. 2006. A teia da vida: uma nova compreensão científica dos seres vivos. Tradução de Newton Roberval Eichemberg. São Paulo: Cultrix.

Cominssion on Global Governance .Our Global Neighborhood - GDRC (1995). Disponível em http://www. 
gdrc.org/u-gov/global-neighbourhood/A Acessado em 15 de junho de 2016.

DALLARI, D.de A. 2007. Elementos de teoria geral do estado. 26 ed. São Paulo: Saraiva.

FERRY, L., 2009.A nova ordem ecológica: a árvore, o animal e o homem. Tradução de Rejane Janowitzer. Rio de Janeito: DIFEL.

FONSECA, I. F.; BURSZTYN, M. 2009. A banalização da sustentabilidade: reflexões sobre governança ambiental em escala local. Sociedade e Estado, Brasília, v. 24, n. 1, p. 17-46, jan./abr.

GADAMER, Hans-Georg. 2001.Gadamer in conversation: reflections and commentary. New Haven, Connecticut: Yale University Press.

GADAMER, Hans-Georg. 1997.Verdade e Método. Petrópolis: Vozes.

HABERLE, P. 1997. Hermenêutica Constitucional, A sociedade aberta dos interpretes da Constituição: Contribuição para a Interpretação Pluralista e 'Procedimental' da Constituição. Trad.: Gilmar Ferreira MENDES. Ed. Sergio Antonio Fabris, Porto Alegre.

HARDIN, G. 1968.’'The Tragedy of the Commons”. Science, vol. 162, No. 3859 (13 de dezembro de 1968), pp. 1243-1248.

JACOBI; P. ROBERTO; SINISGALLI, P. A. A. 2012.Governança ambiental e economia verde. Ciênc. saúde coletiva, Artigo .vol.17 no.6, Rio de Janeiro, June.

JONAS, H. 1995. El principio de responsabilidad: ensaio de uma ética para la civilización tecnológica. Barcelona: Herder.

LEFF, E. 2006. Racionalidade ambiental: a reapropriação social da natureza. Tradução Luis Carlos Cabral. Rio de Janeiro: Civilização Brasileira.

MPF/SE: Justiça Federal proíbe concessão licença de construção em área de proteção ambiental Disponível em noticias. pgr.mpf.mp.br/.../mpf-se-justica-federal-proibe-concessao-licenc Acessado em $22 \mathrm{de}$ abril de 2016.

MCFARLAND, A. N. 2007.Annual Review of Political Science, v. 10, p. 45-66.

MILARÉ, E. 2005. Direito do Ambiente: doutrina, jurisprudência, glossário. $4^{a}$ ed., São Paulo: Revista dos Tribunais.

ROCHA, V. G. 2007. Gestão de resíduos sólidos da Barra dos Coqueiros. Dissertação (Mestrado em Desenvolvimento e Meio Ambiente) - Universidade Federal de Sergipe, São Cristóvão, 174 f..

RUA, M. das G. 1998. Análise de Políticas Públicas: Conceitos Básicos. In: RUA, M. das G.; VALADAO, M. I. O Estudo da Política: Temas Selecionados. Brasília: Paralelo 15.

RUA, M.das G.. 2009. Políticas públicas. Florianópolis: Departamento de Ciências da Administração / UFSC; 
[Brasília] : CAPES : UAB.

SACHS, I. 2002. Caminhos para o desenvolvimento sustentável. 3 ed. Rio de Janeiro: Garamond.

SAGOFF, M. 1998 Is the economy too big for the environment? In: DALLMEYER, D. G.; IKE, A. F. (eds.) Environmental ethics and the global marketplace. Athens: University of Georgia Press,. p. 31-61.

SANTANA, L. 2012. Geotecnologias aplicadas ao estudo da expansão urbana de Barra dos CoqueirosSE, Artigo .VII Connepi- IFTO.

SANTOS, B. de S. 2001.As tensões da modernidade. In: Fórum Social Mundial. Porto Alegre.

SANTOS, B. de S. 2003. Introdução a uma ciência pós-moderna. 4 ed. São Paulo: Graal.

SANTOS, B. de S. 2007. Para além do Pensamento Abissal: das linhas globais a uma ecologia de saberes. Revista crítica de ciências sociais. $78,3-46$.

SANTOS, R. F. dos. 2004. Planejamento Ambiental: teoria e prática. São Paulo: Oficina dos Textos.

SANTOS, S. S. C dos. 2011. Conservação versus conflitos socioambientais (Comunidade Jatobá) no Futuro Parque Estadual das dunas: Barra dos Coqueiros, Sergipe. Dissertação (Mestrado em Desenvolvimento e Meio Ambiente) - Universidade Federal de Sergipe, São Cristóvão.

SEMARH-Secretaria de Estado dos Recursos Hídricos. Relatório Anual 2008. Disponível em 187.17.2.75/ seplagnovo/attachments/.../Relatório\%20de\%20Atividades- \%202008.pdf Acessado em 22 de abril de 2016.

SEMARH- Secretaria de Estado dos Recursos Hídricos. Consulta pública em 18/12/2008. Disponível em www. semarh.se.gov.br/modules/news/article.php?storyid=244. Acessado em 29 de julho de 2016.

SNUC- Sistema Nacional de Unidades de Conservação da Natureza. Regulamentação da Lei 9.9985 sobre Conservação da Natureza, art. 225, \1o, incisos I, II, III e VII da Constituição Federal, . de 18 de julho de 2000 Disponível em www.planalto.gov.br/ccivil 03/leis/L9985.htm Lei 9.9985. Acessado em 06 de maio 2016.

SOUZA, R. W. X. de. Por uma teoria das normas ambientais sob a ótica da natureza como sujeito de direito: quebra de paradigmas. 2013. 125 p. Dissertação (Mestrado em Desenvolvimento e Meio Ambiente) Programa de Pós-Graduação em Desenvolvimento e Meio Ambiente - PRODEMA, Universidade Federal de Sergipe, São Cristóvão 2013. 